\title{
Delayed removal of a deeply migrated pigtail pancreatic stent in a normal pancreatic duct
}
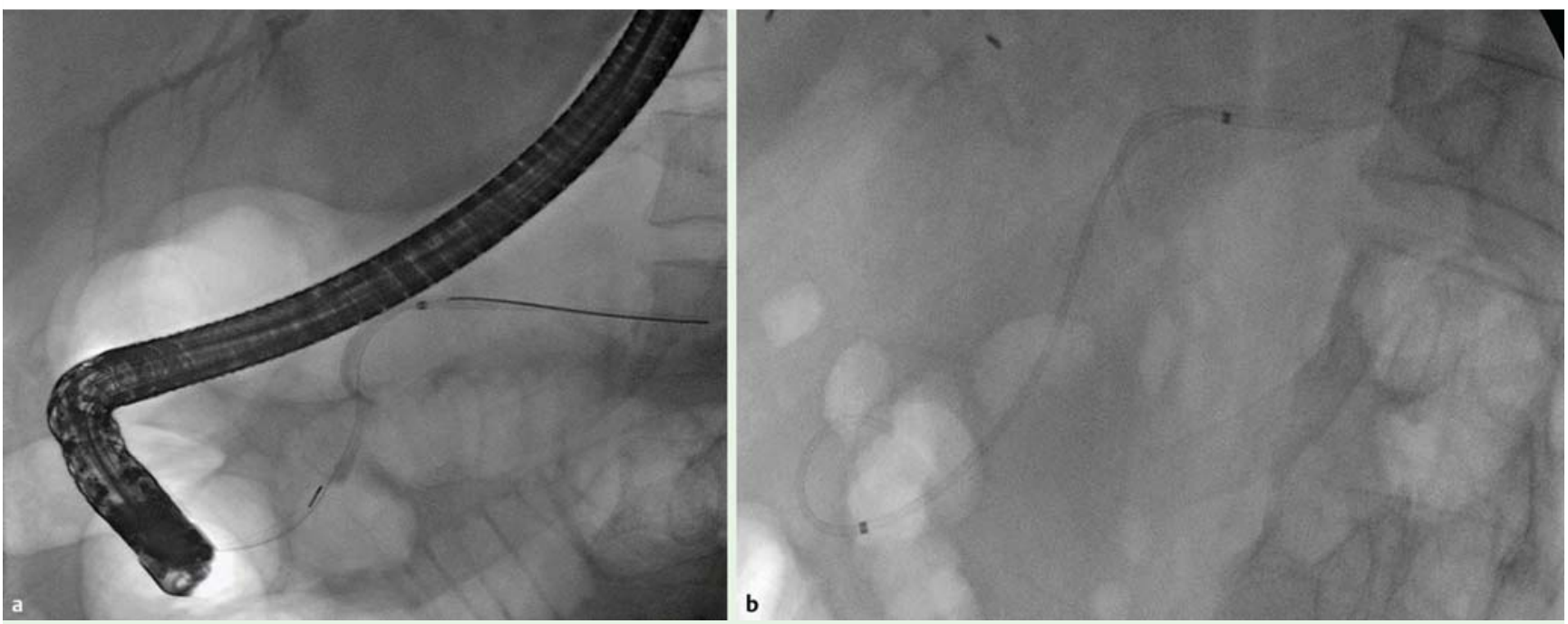

Fig. 1 Unintentionally migrated pigtail pancreatic stent in a 57-year-old man who underwent endoscopic retrograde cholangiopancreatography (ERCP) for multiple bile duct and gallbladder stones. a Unintentional deep inward migration of a pigtail pancreatic stent up to the neck of the normal pancreatic duct. b A second long pancreatic duct stent inserted to prevent post-endoscopic retrograde cholangiopancreatography (ERCP) pancreatitis.

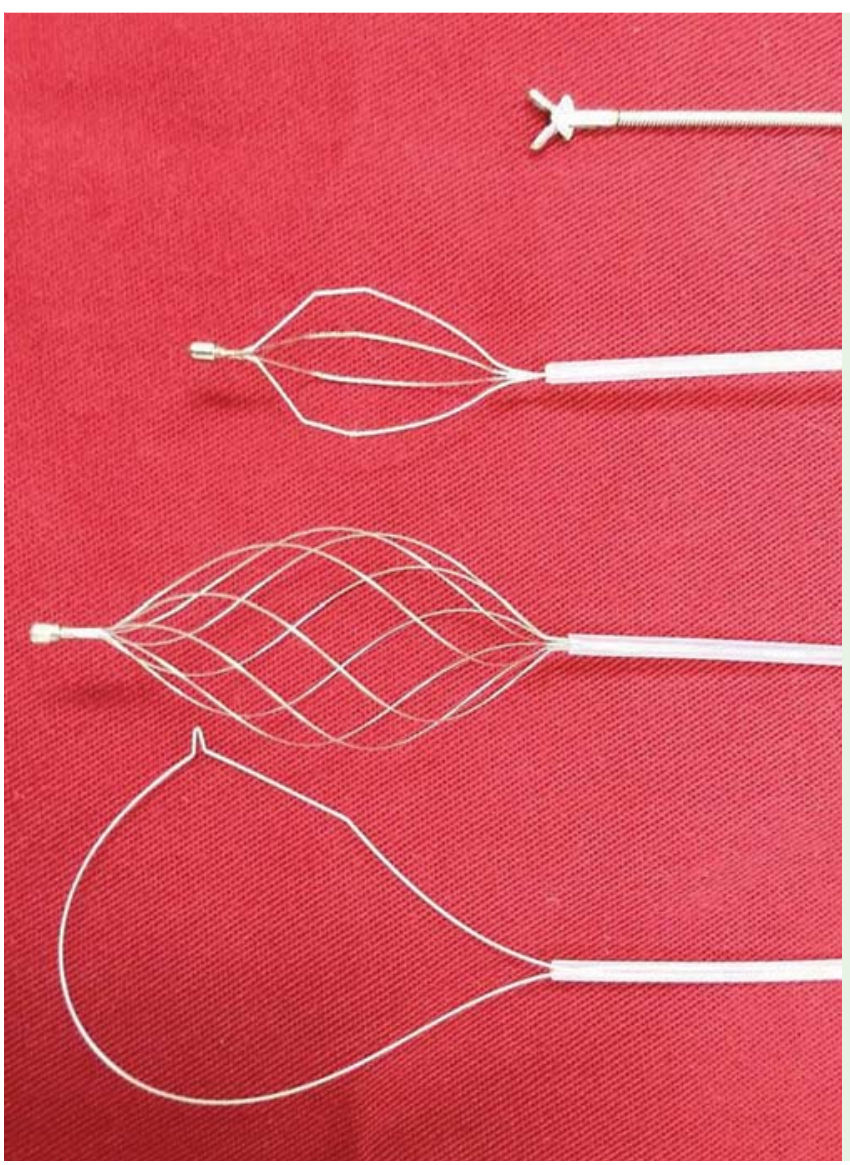

Fig. 2 Comparison of the devices used in attempts to remove the migrated pigtailtype pancreatic stent. From top to bottom: endobiliary biopsy forceps, Dormia basket (MTW Endoskopie, Wesel, Germany), eight-wire Memory ${ }^{\mathrm{TM}}$ basket (MB5-2X4-8, Cook Endoscopy, WinstonSalem, North Carolina, United States), and crescent-shaped snare (SD-7P-1, Olympus Optical, Tokyo, Japan).
A 57-year-old man underwent endoscopic retrograde cholangiopancreatography (ERCP) for multiple bile duct and gallbladder stones. During the ERCP, we attempted to insert a prophylactic 5-Fr, single pigtail pancreatic stent (Cook Endoscopy, Winston-Salem, North Carolina, United States) because biliary cannulation is difficult and the pancreatic duct is frequently cannulated unintentionally; however the pancreatic stent migrated deep into the normal pancreatic duct and the pigtail portion of the stent curled into the inner pancreatic duct ( $\mathbf{F i g} . \mathbf{1}$ a). We attempted to remove the stent immediately using endobiliary biopsy forceps, a conventional snare, and a Dormia basket ( $\bullet$ Fig. 2), as reported in various cases [1-4]; however these methods all failed because the pancreatic duct was of normal size and it was difficult to advance the devices past the neck of the pancreatic duct. Moreover, the curved pigtail head made capture impossible. The repeated attempts at removal only pushed the stent more deeply into the pancreatic duct. Consequently, we inserted a second 9cm-long pancreatic stent to prevent postERCP pancreatitis, removed the biliary stones, and then performed a laparoscopic cholecystectomy. Again, we tried to remove the migrated pancreatic stent, but failed despite trying various methods, 


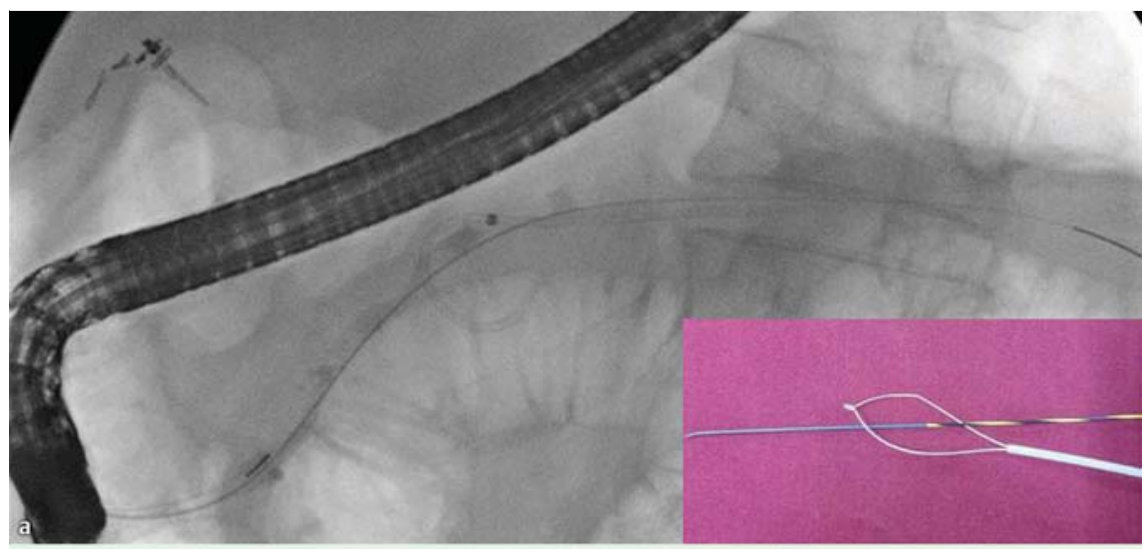

- Various endoscopic techniques have been introduced for removing a proximally migrated pancreatic stent. Typically, however, these migrated stents are the straight type. The single pigtail type stent was developed to prevent spontaneous proximal migration. Nevertheless, unintentional migration is possible, as in our case. Various reported methods were unsuccessful because the normal-sized pancreatic duct and curved pigtail stent prohibited capture with forceps or advancing other capture devices. In this situation, delayed removal following insertion of an additional stent can help to make more space for inserting removal devices. In addition, the relatively small diameter of the sheathed snare that we used is helpful in such cases.

Endoscopy_UCTN_Code_TTT_1AR_2AG

Competing interests: None

\section{Young Kyu Jung ${ }^{1}$, Tae Hoon Lee', Sang-Heum Park ${ }^{1}$, Hyun Jong Choi ${ }^{2}$, Sang-Woo Cha ${ }^{3}$, Jong Ho Moon ${ }^{2}$, Young Deok $\mathrm{Cho}^{3}$}

${ }^{1}$ Digestive Disease Center, Department of Internal Medicine, Soonchunhyang University School of Medicine, Soonchunhyang University Hospital, Cheonan, Republic of Korea

${ }^{2}$ Digestive Disease Center, Department of Internal Medicine, Soonchunhyang University School of Medicine, Soonchunhyang University Hospital, Bucheon, Republic of Korea

${ }^{3}$ Digestive Disease Center, Department of Internal Medicine, Soonchunhyang University School of Medicine, Soonchunhyang University Hospital, Seoul, Republic of Korea

\section{Acknowledgments} $\nabla$

This work was supported by the Soonchunhyang University Research Fund. neck of the normal-sized pancreatic duct. As we needed more space to insert the removal devices, we decided to reinsert the 9-cm-long, 5-Fr pancreatic stent ( $\bullet$ Fig. 1 b), which overlapped the migrated stent, and planned to remove the migrated stent 3-4 months later, hoping that the second stent would cause some duct enlargement.

Finally, 4 months later, we attempted to remove the migrated pigtail pancreatic

stent. After removing the second stent with forceps, we inserted a 0.035 -inch guidewire up to the tail of the pancreas and then inserted a crescent-shaped snare ( $\bullet$ Fig. 2; SD-7P-1, Olympus Optical, Tokyo, Japan) along the guidewire to the body of the pancreas ( $\mathbf{F i g . 3}$ ). This snare has a relatively narrow sheath and monofilament wire ( $\bullet$ Fig.2). Then, following slow release of the snare at the distal tip of the migrated stent, we carefully withdrew the snare, captured the first pancreatic stent, and removed it safely ( $\bullet$ Fig. 3 ). No post-ERCP pancreatitis or other complications developed.

\section{References}

1 Rerknimitr R, Phuangsombat $W$, Naprasert $P$. Endoscopic removal of proximally migrated pancreatic stent by a grasping tripod. Endoscopy 2007; 39: E42

2 Vila JJ, Ruiz-Clavijo D, Fernandez-Urien I et al Endoscopic retrieval of a proximally migrated pancreatic stent: variation of the lasso technique. Endoscopy 2010; 42: E5 -6

3 Sherman S, Hawes RH, Uzer MF et al. Endoscopic stent exchange using a guide wire 
and mini-snare. Gastrointest Endosc 1993; 39: $794-799$

4 Yoon LY, Moon JH, Choi HJ et al. Wire-guided endoscopic snare retrieval of proximally migrated pancreatic stents after endoscopic papillectomy for ampullary adenoma. Gut Liver 2011; 5: 532 - 535

$5 \mathrm{Kim}$ MJ, Han JH, Kang MH et al. Removal of a deeply migrated pancreatic stent in a normal-size pancreatic duct using a modified snare with a cut plastic sheath. Endoscopy 2012; 44: E308-309

\section{Bibliography}

Dol http://dx.doi.org/ 10.1055/s-0034-1390844 Endoscopy 2015; 47: E106-E108 (C) Georg Thieme Verlag KG Stuttgart · New York ISSN 0013-726X

\section{Corresponding author}

Tae Hoon Lee, MD, PhD

Division of Gastroenterology

Department of Internal Medicine

Soonchunhyang University Cheonan Hospital

23-20 Bongmyung-dong

Cheonan

Chungcheongnam-do

330-721

South Korea

Fax: +82-41-5745762

thlee9@lycos.co.kr

thee9@schmc.ac.kr 